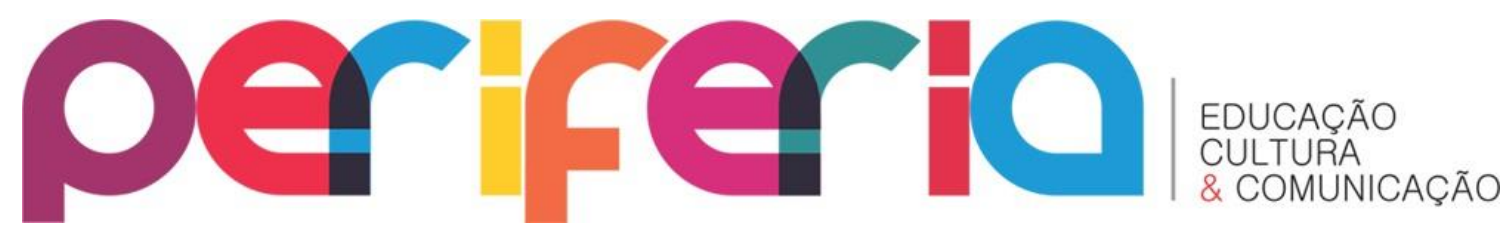

\title{
GOIANA dE SÃO PEDRO, GOYANNA DE DOM PEDRO: LUGARES DE MEMÓRIA E EVOCAÇÕES DO PERIODO IMPERIAL (1822-1889) NO ATRATIVO HISTÓRICO-URBANO DE GOIANA, PERNAMBUCO
}

Rozalves Rafael N. de Lira ${ }^{1}$

Faculdade de Ciências e Tecnologias Prof. Dirson Maciel de Barros

\section{RESUMO}

Este artigo integrou recurso didático complementar da disciplina Tópicos da História do Brasil Imperial (2014.2) do Curso de Licenciatura Plena em História da Faculdade de Ciências e Tecnologias Prof. Dirson Maciel de Barros - FADIMAB (Goiana/PE), e serviu de roteiro discursivo para nossa proposta de aula-visita ao conjunto patrimonial do sítio histórico do município de Goiana, Zona da Mata Norte de Pernambuco. Trabalhando com o conceito de "lugares de memória" (NORA, 1993), buscou perceber no conjunto paisagístico e patrimonial edificado da cidade e em elementos da história local, referências que conduzam a pensar alguns aspectos do período imperial (18221889) através de recortes da história local/regional e uma análise da cidade enquanto "lugar de memória".

Palavras-chave: história urbana; período imperial; patrimônio; história de Goiana/PE.

GOIANA OF SÃO PEDRO, GOYANNA OF DOM PEDRO: PLACES OF MEMORY AND EVOCATIONS OF IMPERIAL PERIOD (1822-1889) IN THE URBAN-HISTORIC ATRACTIVE OF GOIANA, PERNAMBUCO

\section{ABSTRACT}

This text integrates a complementary activity of the discipline Topics in the History of Imperial Brazil (2014), that belongs to the Full Degree Course in History of the College of Science and Technology Professor Dirson Maciel de Barros -FADIMAB (Goiana/PE), it serves as a roadmap for our proposed class-visit to the heritage complex of the historic site of the city of Goiana, Zona da Mata Norte of Pernambuco. It has been working with the concept of "Places of Memory" (NORA, 1993), that aims to discuss

\footnotetext{
1 Mestrando em Educação pelo Programa de Pós-Graduação em Educação da Universidade de Pernambuco (campus Mata Norte). É professor do Departamento de História da Faculdade de Ciências e Tecnologias Prof. Dirson Maciel de Barros - FADIMAB, Goiana/PE.
} 


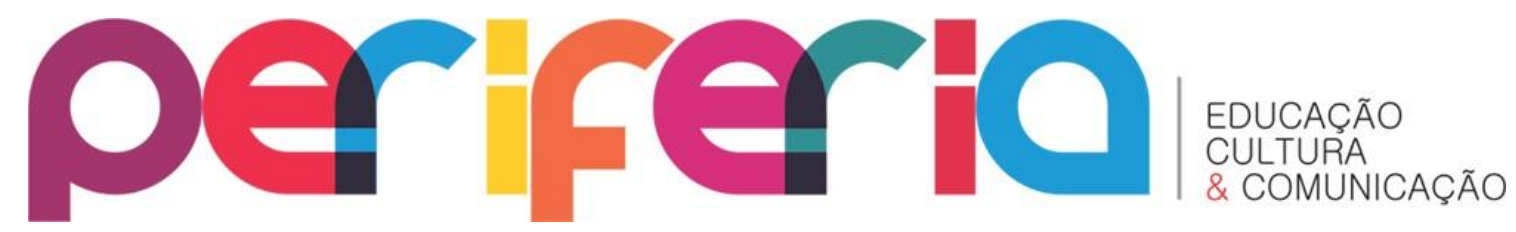

and understand the landscape and heritage complex built the city and local history, these references lead us to think some aspects of the imperial period (1822-1889) through history clippings local/regional and a view of this city how a "place of memory".

Keywords: urban history; imperial period in Brazil; heritage; history of Goiana/PE. 


\section{per \\ ife

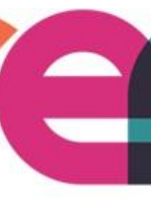

\section{LUGARES, MEMÓRIAS E PATRIMÔNIO NA CONSTRUÇÃO DA HISTÓRIA LOCAL}

As discussões acerca dos "lugares de memória" foram inicialmente pensadas pelo historiador francês Pierre Nora ${ }^{2}$ (1993) tendo como proposta a apreensão de monumentos e lugares que no tempo presente evoquem lembranças e causem indagações sobre o passado. A utilização deste recorte teórico possibilita ao estudante-pesquisador da história ferramentas úteis para a compreensão das ações do homem ao longo do tempo cronológico, em especial, quando este se depara com recursos de memória de caráter patrimonial material, como o são os monumentos e logradouros públicos do sítio histórico da cidade de Goiana.

Cabe ressaltar aqui a importância do patrimônio urbano edificado como fonte histórica e a abrangência do termo patrimônio ${ }^{3}$ tomado no sentido de elementos "que participam da construção do pertencimento, das identidades e da continuidade da experiência social, no âmbito dos processos de formação e transformação" (MARTINS, 2009, p. 281). As cidades estão impregnadas de memória, experiências, cotidiano, sendo o seu patrimônio construído reflexo das sociedades e agrupamentos humanos que as habitam/habitaram, constituindo as referências de identidade e memória de grupo.

Convém pensar um aglomerado urbano ou cidade como resultante de fatores distintos e acumulados ao longo da história que lhe garantem sentido e forma, visto serem as cidades produtos da história (BARROS, 2007). Desta maneira podemos pensar o sítio histórico do município de Goiana como resultante de condicionantes históricas que nos permitem apreendê-lo qual documento capaz de dar pistas para o entendimento do Período Imperial, especificamente sobre como fora este vivenciado e sentido nesta região de Pernambuco.

\footnotetext{
${ }^{2}$ Sobre esta discussão veja-se: NORA, P. Entre memória e história: a problemática dos lugares. São Paulo: EDUSP, 1993.

${ }^{3}$ Para discussões sobre patrimônio veja-se: ASSUNÇÃO, P. Patrimônio. São Paulo: Loyola, 2003. E de sua utilidade para o oficio do historiador seria interessante a observância de: MARTINS, Ana Luiza. Uma construção permanente: fontes para o patrimônio cultural. In: PINSKY, C. B.; LUCA, T. R. (orgs.). O historiador e suas fontes. São Paulo: Contexto, 2009.
} 


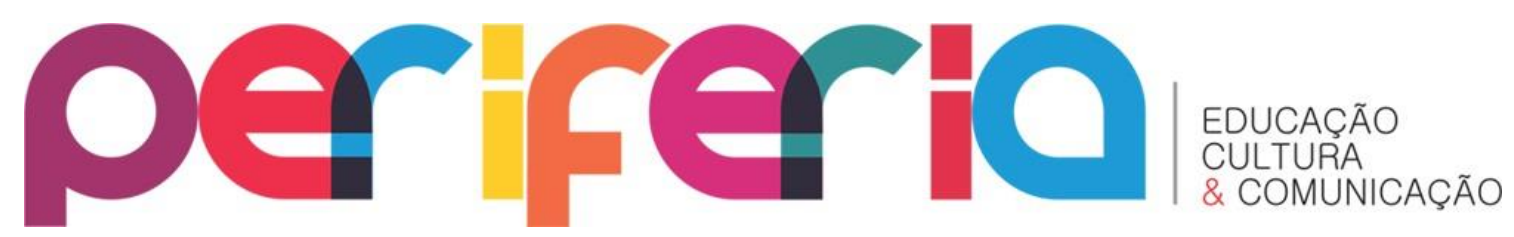

Ao utilizar uma metáfora segundo a qual o historiador pode ser comparado ao ogro da lenda, pois "onde fareja carne humana, sabe que ali está sua caça", Marc Bloch (apud PINSKI; LUCA, 2009, p. 26) muito contribuiu para o debate em torno da ampliação da tipologia de fontes que podem ser utilizadas na "contação" da história, entre elas estão as paisagens e edificações urbanas.

É de acordo com a escolha das fontes que o pesquisador empreende a construção da narrativa historiográfica, pois as fontes não nascem prontas, mas são transformadas em fonte (CAVALCANTI; CABRAL, 2013). É o oficio do historiador que garante as mesmas a sua legitimidade como instrumento contador da história, na realidade, a análise e o questionamento das fontes é que lhe garantem o aspecto de corpus documental.

Neste âmbito as ruas, praças, monumentos e edificações de Goiana nada contam sobre o período imperial se levados em consideração apenas em seu aspecto formal, abstrato. É necessário fazer questionamentos, buscar extrair dos caminhos, pedras e tijolos assentados o que revelam acerca do período e das relações sociais travadas em seus espaços no passado. É preciso relacionar as discussões teóricometodológicas previamente tecidas, traçar paralelos, aproximações e afastamentos entre monumentos, partidos arquitetônicos e memórias para se "contar as histórias".

Igualmente importante neste sentido, é buscar estabelecer correlações entre o conceito e as abordagens pretendidas acerca da educação patrimonial e os aspectos referentes à história local, lembrando que o estudo da história do lugar deve dialogar, portanto, com os elementos da história nacional, pois do contrário, o estudo interessará apenas a "aqueles que lá vivem". Neste trabalho buscamos, partindo do contexto e das experiências históricas vivenciadas em Goiana, "reconhecer sua significância mais ampla" (TOSH, 2011, p. 91), não apenas na construção da história local, mas principalmente para a história nacional durante o período Imperial. 


\section{periferio}

HISTORIANDO OS FATOS: IMPÉRIO DO BRASIL OU REINO DO BRASIL?

A vinda da corte portuguesa para o Brasil em 1808 simbolizou um marco na construção política e ideológica da nação brasileira. Num período de aproximadamente quinze anos, personagens como D. João VI e D. Pedro I alteraram fundamentalmente as regras do jogo e ajudaram a construir, juntamente com as elites locais, a independência política do país em relação a Portugal, cujo corte final de relações ocorre em $1822^{4}$.

Substanciada a independência política, para as elites que encabeçaram o movimento não era cogitado nenhum tipo de reforma social ou econômica radical, por isso manteve-se a escravidão, a economia agroexportadora, o centralismo político e a pouca participação do povo nos espaços de exercício do poder formal, no dizer de Emilia Viotti, "ficaria claro para quem e por quem tinha sido feito o país independente" (COSTA, 2007, p. 39).

Diferente de seus vizinhos latino-americanos, cujo processo de independência política é contemporâneo ao do Brasil e que optaram pelo regime republicano, o novo país organizou-se politicamente em torno de uma monarquia constitucional de caráter autoritário, sob o titulo de Império do Brazil. A adoção deste termo para nomear a jovem nação explica-se pelo fato de que seu pensamento político era de matriz portuguesa, para quem o Império Ultramarino Português, moldado em forma comercial, militar e eclesiástica, construído a partir do século XV durante a era das grandes navegações, era a referência principal. O próprio Pedro I, então com 23 anos ao proclamar o país livre, era português (BOXER, 1980).

Interessa-nos discutir a terminologia utilizada para a nova pátria e pensar etimologicamente a palavra império como sendo sinônimo de: “domínio ou porção administrativa composta por territórios não contíguos ao seu, em geral, ubicados em continentes diferentes" (AULETE, 2004, p. 433). Neste âmbito, parece que a palavra

\footnotetext{
${ }^{4}$ Neste tocante recomendamos as leituras de: PEDREIRA, J; COSTA, F. D. João VI: um príncipe entre dois continentes. São Paulo: Cia. das Letras, 2008; e; MONTEIRO, H. Brasil Império. 3. ed. São Paulo: Ática, 1994.
} 


\section{periferio}

apresenta mais sentido, no caso brasileiro, pela força de uso e referências de matriz tradicionais, já que o Brasil não teria possessões geopolíticas extraterritoriais ${ }^{5}$.

De forma que é apropriado concebermos que o Brasil adotara o termo império, embora na prática constitui-se um reino, pois seu regime político baseava-se na liderança política do monarca ou rei. Sendo apropriado lembrarmos que nunca fomos um império, no sentido estrito do termo, mas aqui utilizamos a expressão período imperial, por tratar-se de expressão típica da divisão clássica da história nacional, durando de 1822 a 1889.

\section{CONTEXTO, TEMPO E ESPAÇO: GOYANNA ${ }^{6}$ NOS TEMPOS DO I IMPÉRIO E DO PERÍODO REGENCIAL (1822-1840)}

A partir deste ponto discutimos a ligação dos "lugares de memória" de Goiana com a história do Brasil Imperial, buscando o "fio da meada" que nos conduza a pensar as referências do período, sua gente e seu modo de agir que os logradouros urbanos evocam. Nesta perspectiva convém lembrar que a cidade deve ser vista como uma sobreposição de camadas, cada uma oriunda de um tempo. Pois, embora privilegiemos o recorte de tempo tido como Imperial, não significa, que memórias da Colônia e da República não estejam presentes na paisagem urbana goianense, até porque como as cidades "costumam atravessar os tempos históricos, costuma ocorrer também uma espécie de superposição de padrões de espacialidade em um mesmo espaço urbano" (BARROS, 2007, p. 25).

Econômica e socialmente, era Goiana, já nas décadas que antecedem o final do século XVIII, a mais próspera cidade do interior de Pernambuco. Seu largo histórico de participação nas lutas cívicas que envolviam os temas de preocupação nacional, como

\footnotetext{
${ }^{5}$ Alguns especialistas apontam como indícios de práticas imperialistas nesta época, os episódios da Guerra da Cisplatina (1825) e Guerra do Paraguai (1864-1870). Sobre estes dois conflitos pode-se consultar: COSTA, E. V. Da monarquia à república: momentos decisivos. 8. ed. São Paulo: UNESP, 2007; CHIAVENATTO, J. Genocídio americano: a guerra do Paraguai. São Paulo: Brasiliense, 1982.

${ }^{6}$ Optamos por utilizar a grafia antiga do nome da cidade, conforme era de uso no Período Imperial.
} 


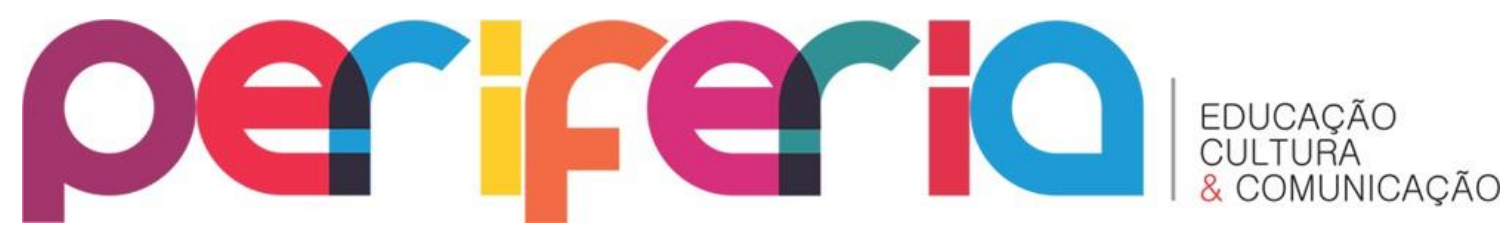

a Independência, as Rebeliões Regionais (1817, 1821, 1824, 18487), a Abolição da Escravidão e a República, denunciam sua importância como núcleo urbano ao longo de todo o século XIX8.

Sobre o cenário goianense no início do século XIX, quando da fase de préindependência e de estadia da Família Real Portuguesa no Brasil, temos o testemunho de Henry Koster, um português, filho de ingleses, que chega a Pernambuco em 1809, em busca de clima tropical para curar uma tuberculose, arrendando o engenho Jaguaribe, na ilha de Itamaracá, em 1812. Este jovem realizou algumas viagens pelo Nordeste, à época Norte do Brasil, das quais resultou a escrita do livro Travels in Brazil, publicado em Londres em 1816. De sua passagem por Goiana em 1810, ele registraria:

A vila de Goiana, uma das maiores e mais florescentes da capitania de Pernambuco, está situada às margens do rio de mesmo nome. As casas possuem um só andar e as ruas são largas, mas sem calçamento. Uma das principais é tão ampla que admitiu a construção de uma grande igreja, numa das extremidades, e a extensão da rua é considerável em ambos os lados do edifício ${ }^{9}$. [...]. O número de habitantes de 4 a 5 mil cresce diariamente. Há também lojas e o comércio com o interior é intenso. Nas ruas sempre são encontrados numerosos matutos, camponeses que vêm vender seus produtos e comprar manufaturas de que tem necessidade. Nas imediações existem muitos e excelentes canaviais (KOSTER, 1978, p. 648).

Entre os fatores que explicam a prosperidade do lugar naqueles idos, podemos citar a sua localização geográfica nas fronteiras com a Paraíba e com outras cidades de pouca expressão, o que the aferia condição de polo econômico e político regional, situação observada desde a fase colonial. Além de que, a lei provincial de $n \circ 86$, de 5 de maio de 1840, que a elevou a condição de cidade, definia-Ihe os seguintes limites

\footnotetext{
7 Sobre estes movimentos pode-se consultar: AQUINO, R. L. Pernambuco em chamas: revoltas e revoluções em Pernambuco. Recife: Massangana, 2009; e: MACHADO, T. J. As insurreições liberais em Goiana, 1817-1824. Recife: FUNDARPE, 1990.

${ }^{8}$ Goiana tem sua formação histórica, política e social ligada durante os três primeiros séculos da colonização a Capitania de Itamaracá, neste tocante seria interessante a observância de: ANDRADE, M. C. Itamaracá, uma capitania frustrada. Recife: FIDEM, CEHM, 1999; e: JORDÃO FILHO, A. Povoamento, hegemonia e declínio de Goiana. Recife: SEDUC, 1977.

${ }^{9}$ Ele se referia à Rua Direita e a Igreja Matriz de Nsra. do Rosário dos Homens Brancos.
} 


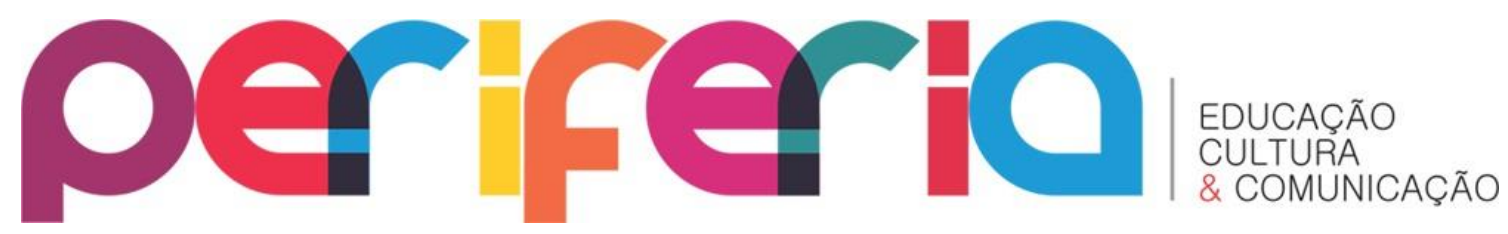

geopolíticos: "ao norte com o termo da Paraíba, a leste com o oceano, ao sul com o termo de Igarassu e a oeste com o de Limoeiro" (HONORATO, 1976, p. 51). Tais dimensões territoriais, que hoje compreende parcela significativa de municípios da Mata Norte, Ihe garantia vultosa fonte de renda proveniente da produção açucareira dos engenhos instalados em sua jurisdição.

Havia ainda em Goiana núcleos de produção vidraceira e ceramista, além de importante feira de gado e couro que ocorria desde meados do século XVIII em Nossa Senhora do Ó (hoje Tupaóca, município de Aliança/PE), atraindo pessoas das províncias vizinhas e vaqueiros que traziam gado desde as distantes províncias do Piauí e Ceará. Outra feira de gado funcionava nas proximidades da cidade já por volta das primeiras décadas do século XIX, "entre a vila e o engenho Mariúna em uma praça onde era feita a feira de gado e nas proximidades um curtume" (SILVA, 2011, p. 28).

Tudo indica que esta feira localizava-se nas imediações da atual Av. Nunes Machado, centro de Goiana, haja vista que em meados do século XIX, a região não compunha mancha urbana contigua a cidade, mas compunha as terras do engenho Mariúna, cuja sede situava-se nos arrabaldes do atual bairro Vila Bom Tempo, em local conhecido por Mariúna (próximo ao viaduto da BR-101), onde parece haver vestígios da senzala do engenho em um conjunto de casas em "estilo senzala". Corrobora o fato ainda, a existência de uma rua chamada do Curtume nas imediações da Av. Nunes Machado.

Outro fator primordial no desenvolvimento de Goiana durante o período imperial seria a ocorrência de seu porto fluvial, localizado à cerca de $20 \mathrm{~km}$ do litoral, cumprindo a função de escoadouro da produção agrícola da Mata Norte e de povoados da Paraíba, principalmente de algodão e açúcar, e abastecedouro da mesma região de manufaturas e outros itens necessários.

O comércio era enorme daquela época. Não existindo ainda estrada de ferro, todos os municípios vizinhos vinham se abastecer em Goiana, [...]. Daí, o extraordinário movimento comercial da cidade, 


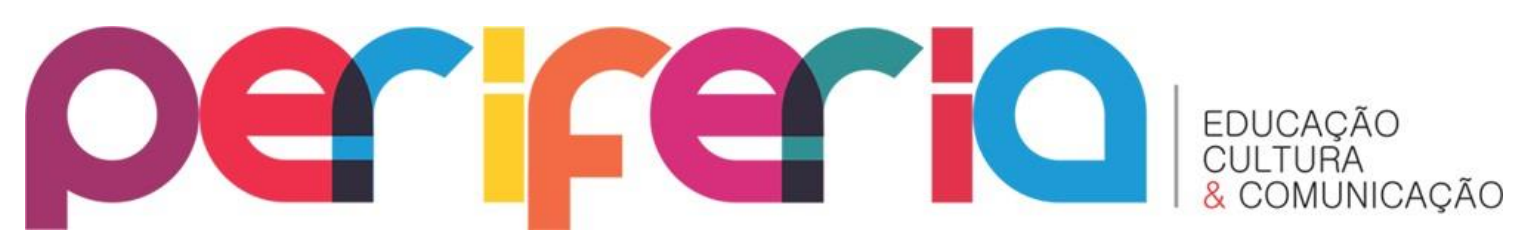

contando a Rua do Meio ${ }^{10}$ com 26 lojas de fazendas, comprando alguns comerciantes direto da Europa. Os armazéns e as casas comerciais funcionavam até tarde para atender a freguesia que vinha de grande parte do interior de Pernambuco e Paraíba (PINTO, 1968, p. 153).

Por este porto, que ligava a região ao Recife e a partes das províncias vizinhas, não entravam e saiam apenas itens de comércio, mas principalmente pessoas, trocas culturais, ideias e noticias que tornariam Goiana a expoente principal da participação política e cultural da Mata Norte na vida política e social da Província de Pernambuco durante o Império brasileiro.

As facilidades de acesso "aos mundos exteriores" pelo porto e os lucros ganhos com as atividades açucareiras e comerciais faziam com que a elite local de proprietários rurais e comerciantes demonstrasse o seu poderio através da ostentação de produtos importados da capital da província e até do exterior. Já na época da visitação de Koster a Goiana (1810) ele nos deixa surpreender com o seguinte comentário: "a rivalidade entre as famílias aumenta o consumo de objetos de luxo" (1978, p. 648) como: "fardos de tecidos, especiais encomendas de baixelas, finas louças, perfumes, lustres de cristal" e artigos e instrumentos musicais (SENA, 2008, p. 147; MACHADO, 1990, p. 13).

A difusão de hábitos musicais entre ricos e pobres goianenses conferiria à cidade a tradição das bandas musicais centenárias, sendo a Sociedade Musical Curica $^{11}$, fundada em 1848, considerada a mais antiga banda em atividade da América Latina. A fundação das bandas musicais de Goiana ocorre em um período de efervescência e acirramento da rivalidade entre as duas principais correntes políticas

\footnotetext{
${ }^{10}$ Rua localizada entre as quadras que compõem a antiga zona portuária e a Rua Direita, no centro histórico de Goiana, outrora centro de comércio lojista de atacado e varejo da cidade, contando com "Iojas de fazendas, ferragens, miudezas, estivas, armazéns de açúcar e cereais" (SENA, 2008, p.148).

${ }^{11} \mathrm{Em} 2005$ a banda recebeu o titulo estadual de Patrimônio Vivo de Pernambuco. Sobre sua trajetória para aquisição do titulo veja-se: AMORIM, M. A. Banda Musical Curica. In: Patrimônios vivos de Pernambuco. Recife: FUNDARPE, 2010.
} 


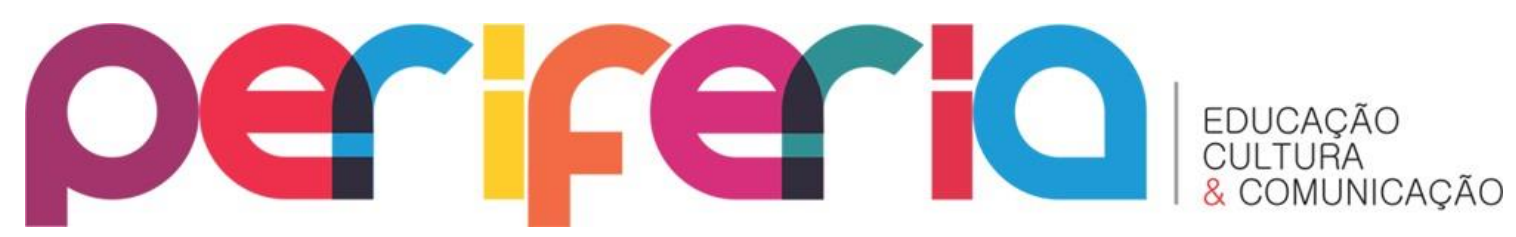

nacionais durante o Império: os partidos Liberal e Conservador. A Curica estaria ligada ao Partido Conservador local (SENA, 2008; GOIANA. 2010) ${ }^{12}$.

Como demonstração da rivalidade entre os partidos manifestada a nível local, em 1849, um ano após a fundação da Curica, criou-se a Banda Musical 12 de Outubro, conhecida como Saboeira, ligada ao Partido Liberal. Surgidas num ambiente de conflitos partidários, vez ou outra, a rivalidade virava violência física, visto que "as histórias de inimizade figadal entre as duas bandas foram escritas com sangue. Entre pontapés e lances de capoeira, gritava-se: 'Viva a Curica! Morra a Saboeira!' E viceversa" (AMORIM, 2010, p. 49).

Pelo elenco de informações aqui expostas, percebe-se que tinha a cidade de Goiana nos "tempos dos Imperadores" certo clima de animação cultural, contando com teatros, escolas de música e dança e jornais. Dispondo da primeira tipografia instalada na Província de Pernambuco, em 1823, viu circular dezessete jornais de variadas tendências políticas ao longo do século XIX, sendo O Oriente, "o primeiro jornal impresso na cidade" (CARVALHO apud SENA, 2008, p. 388). Os símbolos da animação econômica, social e cultural de Goiana naquele momento, estão manifestados em sua paisagem urbana contemporânea, cabendo ao pesquisador decifrá-los.

\section{SEDE DO IMPÉRIO POR UM DIA E OUTRAS VIVÊNCIAS: MEMÓRIAS DO II IMPÉRIO EM GOIANA (1840-1889)}

Capitulo que reforça a importância da cidade nestes idos é o da visita do Imperador D. Pedro II em 1859, aos 33 anos de idade, quando de sua visitação a Província de Pernambuco.

Ora, vivia naquele momento o regime monárquico brasileiro uma fase importante de consolidação e amadurecimento político, visto que as rebeliões regionais ocorridas entre os anos 30 e 40 do século XIX haviam sido debeladas, de

\footnotetext{
12 Sobre as configurações políticas do período imperial, recomendamos: LIMA, M. O. O império brasileiro: 1822-1889. Brasília: UNB, 1986.
} 


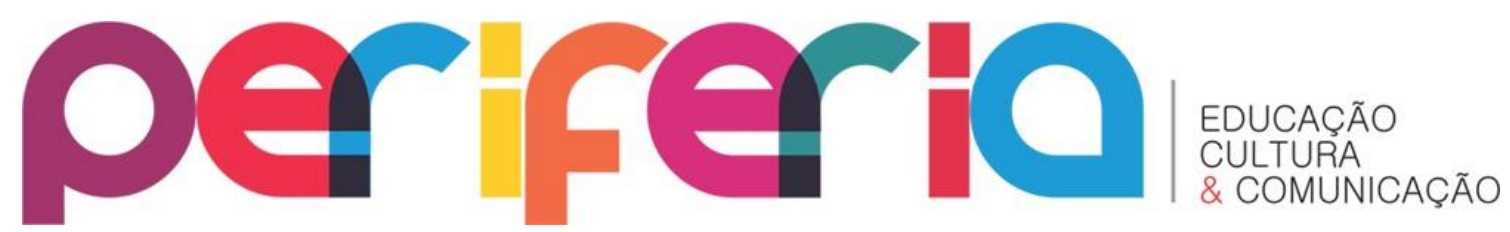

forma que as viagens realizadas pelo Imperador pelas províncias tinham a tônica de fazer-Ihe conhecer o vasto país que governava, afirmar sua presença política e, certificar-se da consolidação da unidade nacional. Esta década pode ser descrita como importante para a construção de uma identidade nacional brasileira, em detrimento dos regionalismos (ANDRADE, 1999) ${ }^{13}$.

D. Pedro II chega ao Recife na manhã de 22 de novembro de 1859, acompanhado da Família Imperial e de grande comitiva de aliados e empregados, para uma estada de mais de duas semanas percorrendo algumas das principais vilas e cidades da província.

Durante boa parte de sua estadia em Pernambuco, o Palácio do Governo de Recife, construído em 1841, tornou-se sede oficial do império e hospedagem da Família Imperial. Tanto o prédio quanto o pátio frontal a este, chamado de Largo do Erário, receberam a partir de então os nomes de Campo e Palácio do Campo das Princesas (atual Praça da República, bairro de Santo Antônio, Recife), em homenagem as princesas Isabel e Leopoldina, filhas de D. Pedro II (ANDRADE, 1999).

Em cinco de dezembro viaja para Goiana, fazendo o percurso pela rota terrestre que partindo do Recife atingia a cidade, nas imediações das atuais ruas da Praia e Manoel Borba (à época Rua da Imperatriz), hoje vias integradas a parte central da cidade, mas que naquele momento constituíam rotas de saída e entrada do núcleo urbano. Chegando no fim da tarde e pernoitando no engenho Itapirema, na manhã do dia 6, a caminho da cidade, passa pelo engenho Cajueiro, onde uma queima de fogos anuncia sua chegada (GOIANA, 2010).

\footnotetext{
${ }^{13}$ Apaixonado por fotografia e pela prática da escrita, D. Pedro II anotava suas impressões e experiências dos locais que visitava. Seus registros resultaram num acervo de quase 30 mil fotos de lugares visitados no Brasil e no exterior (EUA, Europa, África e Oriente Médio), além de anotações e cartas. Em 2011, a representação da UNESCO no Brasil concedeu a 871 documentos ligados aos relatos de viagem do imperador o registro nacional do Programa Memória do Mundo (ANDRADE, 2004). De sua visita à Pernambuco resultou o texto: PEDRO II, Imperador. Viagem a Pernambuco em 1859. Revista do Arquivo Público, Recife, v. 5-6, n. 7-8, 1950/1951. Acerca do modo de governar e da personalidade de D. Pedro II, seria proveitoso ler: SCHWARCZ, L. M. As Barbas do Imperador: D. Pedro II, um Monarca nos Trópicos. São Paulo, Cia. das Letras, 1998. E: SOUZA, F. H. Do poder moderador. Brasília: Senado Federal, 1978.
} 


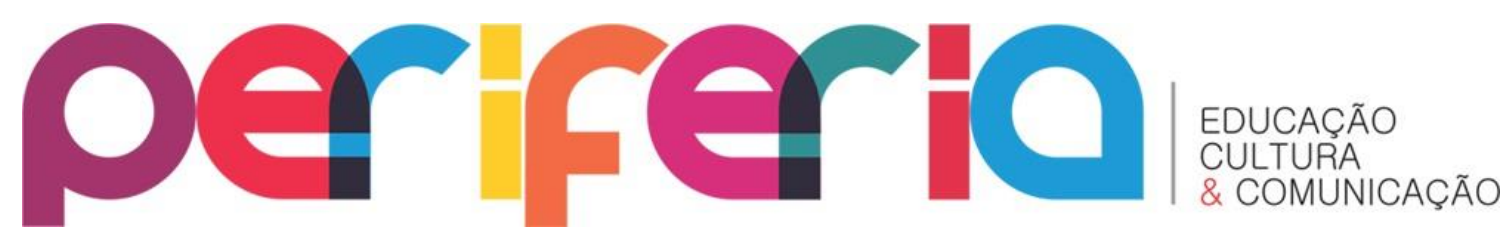

Chegando à cidade, é recepcionado na Rua da Imperatriz (acesso principal para quem vinha no sentido Recife) pelas lideranças local dos partidos conservador e liberal, respectivamente, os barões de Bujary, Antônio Francisco Pereira, e o III barão de Goiana, João Joaquim da Cunha Rego Barros, opositores políticos que disputavam o comando regional. É o barão de Bujary, na condição de presidente da Câmara Municipal, quem entrega as chaves da cidade ao Imperador, um ato simbólico que indicava a lealdade da cidade ao estadista, neste sentido, a cidade de Goyanna, cujo padroeiro era São Pedro, estava agora sob a proteção de D. Pedro (GOIANA, 2010).

A lógica da política pedrana envolvia a presença física do estadista para exercício do poder. Quando viajava pelo interior do país, o Imperador instituía, simbolicamente, o local onde se hospedava como Paço Imperial. Em Goiana, este local teria sido o sobrado do major Manoel Pinheiro da Gouveia, localizado à Rua Direita, embora não haja consenso sobre este local entre os historiógrafos de Goiana (SENA, 2008; GOIANA, 2010) $)^{14}$.

Sobre o clima instalado na cidade quando da visitação, registra-se que:

As ruas principais foram embandeiradas, soltaram-se girândolas, a cidade encheu-se de gente de outras localidades, ansiosas pela rara oportunidade de ver de perto e conhecer o Imperador. As bandas de música Saboeira e Curica e a do 40 Batalhão do Recife tocaram em homenagem ao ilustre viajante, que visitou as igrejas locais, [...]. Assistiu à missa solene na Igreja Matriz e presidiu a reuniões políticas, entre as quais se tratou da construção do Canal de Goiana e da pacificação do Partido Conservador desta cidade, [...]. O beija-mão, tradicional cerimônia de respeito e vassalagem ao Rei, ocorreu, após o Te-Deum, realizado na Igreja Matriz, no Paço Municipal (SENA, 2010, p. 140).

Um fato importante na configuração social e espacial da Goiana Imperial, e que deve ter sido percebido pelo Imperador, era que os templos religiosos católicos distribuíam-se na geografia urbana de forma excludente e segregacionista levando em

\footnotetext{
${ }^{14}$ Sobre as possibilidades para local de estalagem de D. Pedro II em Goiana, consulte-se: SENA, J. F. Onde se hospedou o Imperador?. In: Goiana em versos e prosa.
} 


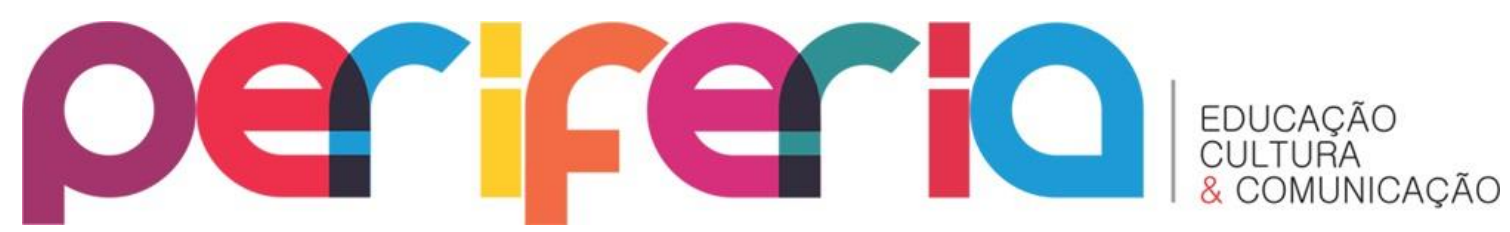

consideração os aspectos étnico-raciais ${ }^{15}$ e econômicos dos grupos usuários dos mesmos (HONORATO, 1976, p. 51), haja vista que

A separação entre as classes sociais era grande, havia uma igreja de Nossa Senhora do Rosário dos Pretos, uma de Nossa Senhora do Amparo dos Pardos Livres e a de Nossa Senhora da Conceição dos Pardos Cativos. Além da segregação entre brancos e homens de cor, segregava-se também os pretos dos pardos, e dentre estes, os livres dos cativos. O hospital ficava ao lado da Misericórdia, era bem instalado, mas não atendia pessoas pobres (ANDRADE, 1999, p. 102).

A visita finda na manhã do dia 7, com o Imperador e sua comitiva no porto da cidade dirigindo-se a freguesia (hoje distrito) de Tejucupapo, indo conhecer o local conhecido como Trincheiras, lugar de memória da época de dominação holandesa sobre o Nordeste do Brasil (1630-1654), onde em 1646, ocorre um embate entre mulheres locais e alguns soldados holandeses (SENA, 2008).

Dois eventos ocorridos na cidade no século XX apontam o desejo de se rememorar esta visitação, indicando como as referências à monarquia e à Família Imperial permanecem vivas no imaginário coletivo do lugar, sendo: as visitas de D. Pedro Henrique de Orleans e Bragança em 1968, "numa visita sentimental, com o interesse de percorrer, a pé, as ruas antigas, visitadas por seu bisavô", e D. Bertrand de Orleans e Bragança, em 1993, considerado então, segundo na linha sucessória da Família Imperial brasileira (NASCIMENTO, 1996, p. 107); o outro, seria a realização da Cavalgada do Imperador, um passeio equestre anual na data de aniversário da visitação (seis de dezembro), percorrendo os principais pontos por onde "teria passado o imperador", partindo do sítio histórico até o distrito de Tejucupapo.

A partir dos anos 60 do século XIX o contexto social e político nacional e provincial seria marcado por relativa estabilidade política, prosperidade econômica e incentivo ao uso de novas tecnologias, embora o Império tivesse ainda sérios

\footnotetext{
${ }^{15}$ As oito igrejas que integram o sítio histórico de Goiana são tombadas como patrimônio histórico nacional desde 1938 pelo antigo Serviço de Patrimônio Histórico e Artístico Nacional - SPHAN (embrião do atual IPHAN). Importante estudo das relações étnico-raciais na religiosidade da Goiana dezenovista pode ser observado em: SILVA, M. J. S. Devoção e resistência: as irmandades de homens pretos de Goiana (1830-1850). Dissertação de Mestrado em Ciências da Religião. Universidade Católica de Pernambuco - UNICAP, Recife, 2010.
} 


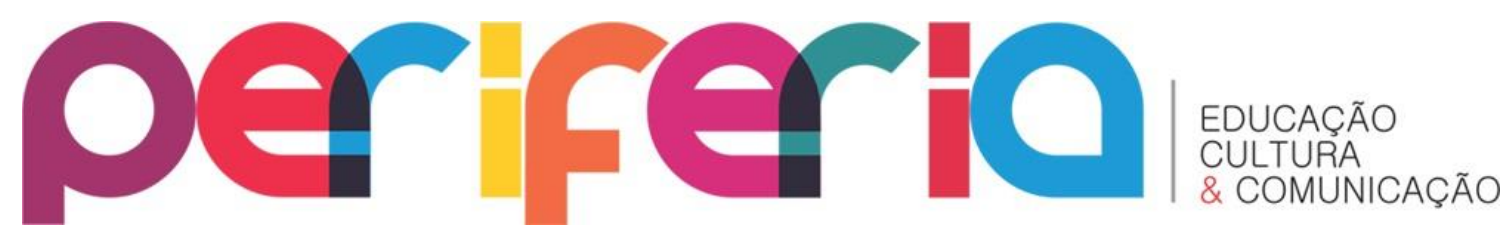

problemas a resolver, principalmente os que se relacionavam ao trabalho escravo e à necessidade de eliminá-lo, haja vista que a maior parte dos países latino-americanos já o tinham feito (ANDRADE, 2004).

Em Goiana esta fase do Período Imperial será marcada pelo auge de suas atividades econômicas. Entre os símbolos do desenvolvimento econômico da cidade nesta fase, pode-se apontar a instalação de algumas instituições, órgãos e entidades de fins diversos, entre os quais: o Instituto Histórico de Goiana em 1870, instalado na igreja de Nsra. do Amparo; a Loja Maçônica Fraternidade e Progresso em 1874, funcionando em sobrado da rua Direita, considerada a "primeira instalada no interior do Estado" (GOIANA, 2010, p. 64), em cujo pavimento térreo funcionaria a partir de 1876 o Gabinete de Leitura de Goiana, uma das poucas bibliotecas do interior à época, e; a instalação de um cemitério secular em 1876.

Mas este é o momento também que marca o inicio do declínio de Goiana enquanto polo urbano regional, figurando entre os fatores que explicam o desenrolar deste quadro, ocorrências de nível provincial e local.

A nível provincial, a ocorrência de crises nas culturas canavieira e algodoeira, atividades das quais muito dependia a cidade, e também o fato de a instalação em Pernambuco dos transportes ferroviários, inaugurados em 1858 com a linha Recife Cabo de Santo Agostinho, ignorar Goiana. Os ramais que fariam a ligação da capital com a Mata Norte do Estado, atingiriam cidades como Nazaré da Mata em 1882, e Timbaúba em 1888, ignorando aquela, tornando seu porto, apesar das obras de alargamento concluídas em 1871, inexpressivo (ANDRADE, 1997; GOIANA, 2010).

As disputas ocorridas na cidade pelo poder assumem significativa parcela de participação no processo de decadência do lugar. A rivalidade política entre o barão de Bujary e o III barão de Goiana causou verdadeiros episódios de vaidade e intriga que contribuíram para a obstrução do porto, seu principal atrativo logístico-comercial, como se percebe no seguinte comentário:

[...], o comendador Antônio Alves Viana, rendeiro do Engenho Novo e pau-mandado do barão de Goiana - João Joaquim da Cunha Rego 


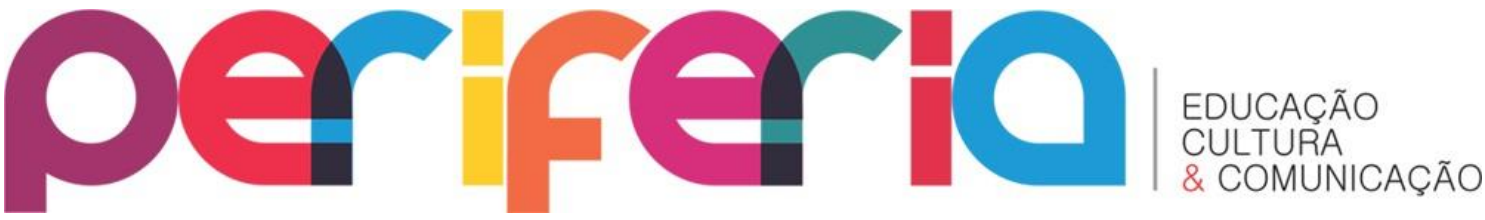

Barros - construiu uma barragem em frente ao seu engenho, local de bifurcação do Capibaribe-mirim, desviando todas as águas que desciam para Goiana para o lado do rio Jacaré; e o rio Goiana começou a secar, transformando-se em um rio morto. Foram infrutíferas as providências para a desobstrução da barragem, pois o caso era político, e o barão era tio do Ministro do Império João Alfredo (SOUZA, 2005, p. 10).

Além destes fatos acima elencados temos um episódio caracterizado pelo espancamento de comerciantes portugueses passado na cidade em 1872, conhecido como "A patriotada ou mata, mata, marinheiro", motivado pelo conhecimento de sátiras publicadas na revista portuguesa As Farpas um ano antes, quando o Imperador Pedro II, visitava a Europa. A publicação de autoria dos escritores portugueses Eça de Queiroz e Ramalho Ortigão, zombava do comportamento do monarca brasileiro, comportamento este que destoava dos hábitos culturais das elites europeias, visto que o monarca havia sido totalmente educado no Brasil (MACHADO, 1990, p. 8; SILVA, 2011).

Neste momento contava o comércio goianense com significativa parcela de comerciantes portugueses à semelhança do que ocorria em outras cidades comerciais do Brasil. Na noite de 29 de julho daquele ano, foi organizada uma passeata na Rua Direita que culminou em violência, resultando em espancamentos, depredação de casas e lojas e o pior, a fuga dos portugueses da cidade, juntamente com seus estabelecimentos comerciais, com destino as cidades do Recife e Nazaré da Mata (Mata Norte pernambucana), prejudicando o comércio local (MACHADO, 1990; SENA, 2008).

$\mathrm{Na}$ década final do Império (1880), o cenário nacional seria marcado pelo acirramento das questões ligadas a abolição da escravidão ${ }^{16}$ e uma maior adesão à causa do republicanismo, indicando que o regime monárquico enfraquecia.

Em Goiana, o movimento abolicionista contou com a formação de sociedades como o Clube do Cupim e o Clube Abolicionista, fundados em 1885. Bazilio Machado,

${ }^{16}$ Sobre a campanha abolicionista veja-se: QUEIRÓZ, S. R. R. A abolição da escravidão. São Paulo: Brasiliense, 1981. 


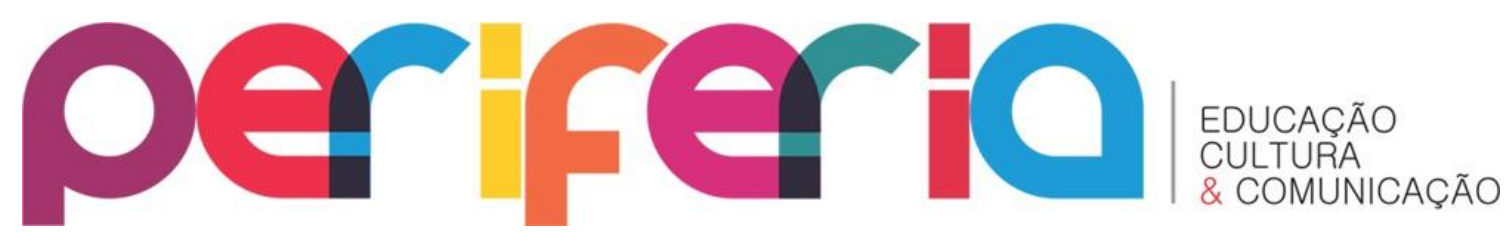

um sapateiro, membro do Clube do Cupim, se destacaria em Goiana por disfarçar-se de vendedor ambulante e peregrinar pelos engenhos da região "convencendo escravos a fugir para o Ceará", província que havia tornado seus escravos livres em 1884 (GOIANA, 2010, p. 66).

A popularidade da causa, aliada ao fato de que novas modalidades de trabalho como o assalariado, o sistema de meia e o cambão, estarem sendo utilizados já há algum tempo em Goiana, serão contributos ao fato desta libertar seus escravos em 25 de março de 1888 , sendo a primeira cidade pernambucana a fazê-lo, antes da Lei João Alfredo ou Lei Áurea, de 13 de maio daquele ano (MACHADO, 1990; NASCIMENTO, 1996).

O movimento republicano ${ }^{17}$, que visava o fim da monarquia, também teve suas representações em Goiana. Em 1888 realizou-se a I Conferência para a Propaganda da República fora da capital provincial, na sede da Sociedade Dançante Terpsicore, na Rua Direita. E em 1889, o propagandista republicano Silva Jardim de visita a Pernambuco, vem à Goiana (GOIANA, 2010).

Para finalizar a construção deste panorama de Goiana à época dos imperadores do Brasil, trazemos um interessante comentário publicado no jornal Diário de Goyanna em 1889, intitulado "Goyanna em decadência" e que pelo tom da crítica, soa oportuno ainda na contemporaneidade:

Enquanto as localidades vizinhas cercavam-se de melhoramentos mais ou menos consideráveis, enquanto por um e por outro lado se projectava [sic] e se levava a effeito [sic] a construcção [sic] de vias férreas, Goyanna, entregue as especulações de uma mercancia egoísta e ao jogo constante de infructiferos [sic] interesses de uma baixa política de aldeia que só tem servido para inocentar criminosos, satisfazer mesquinhas paixões partidárias e crear [sic] patentes e títulos para aquelles [sic] a quem foi reservado o papel de comparsas em todas essas escenas [sic] de abatimento geral, [...].[...]. Goyanna decahio [sic] a falta de melhoramentos. Os culpados são os seus representantes, somos todos nós que não sabemos colocar a

\footnotetext{
${ }^{17}$ Sobre a implantação da República no Brasil interessante discussão pode ser apreciada em: CARVALHO, J. M. Os bestializados. O Rio de Janeiro e a República que não foi. São Paulo: Companhia das Letras, 1987.
} 


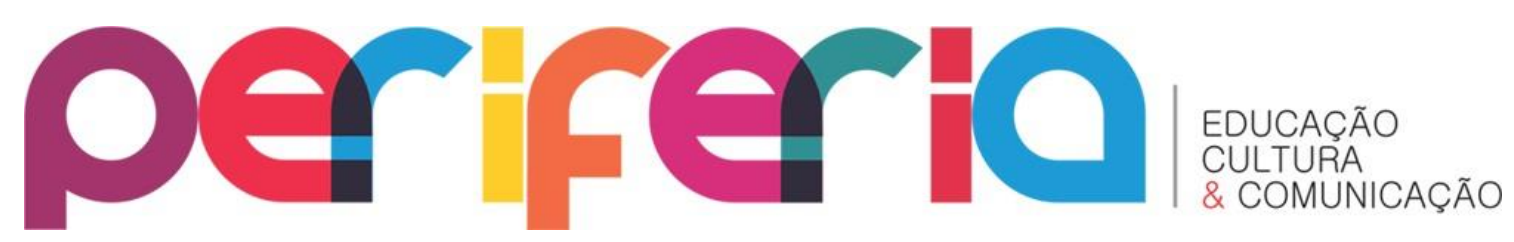

felicidade de nossa terra acima das baixezas locaes [...] (Apud GOIANA, 2010, p. 67).

\section{PARA NÃO CONCLUIR: ALGUMAS CONSIDERAÇÕES FINAIS}

Pensando a cidade enquanto objeto de estudo, Walter Benjamin, propôs uma forma de abordagem que privilegiasse enxergá-la como sendo "um mundo todo nos detalhes do cotidiano" (Apud RAMINELLI, 1997, p. 197). Este aporte metodológico nos incentiva a perceber nos aspectos materiais da paisagem urbana os modos de vida das sociedades que a habitam/habitaram, suas criações, anseios e fatos que alimentam sua memória (BARROS, 2004).

Ao (re)visitarmos o atrativo urbano-histórico da cidade de Goiana munidos de tais referências, percebemos o quanto a cidade significava neste período e o quanto ainda guarda de memórias e evocações do período em que o Brasil esteve sob o regime político imperial, reveladas em seu patrimônio material edificado e fisionomia urbana.

No século XIX, Goiana e sua gente orgulhavam-se de sua participação nos movimentos mais expressivos da política regional e nacional, fazendo com que através de sua Câmara Municipal, a Mata Norte do Estado estivesse representada e participasse ativamente nos assuntos políticos do Império. Na contemporaneidade, historiadores, historiógrafos e goianenses em geral, evocam, com saudade e bairrismo extremados, as memórias da época em que dada a sua importância, a cidade recebia visita de estadistas, como ocorre em 1859 com a vinda de D. Pedro II, e formava políticos para ocupar cargos nas esferas provincial e nacional, caso de João Alfredo Correia de Oliveira, ministro do II Império.

Mas ao empreendermos a analise dos fatores que determinaram o fim do crescimento político e econômico da cidade percebemos a influência deletéria e perversa das intrigas políticas e do mero jogo vaidoso do poder pelo poder como sendo uma das razões principais. Sem sombra de dúvidas, o quadro analisado revela um passado instigante e inspirador a ser rememorado em tempos em que são 


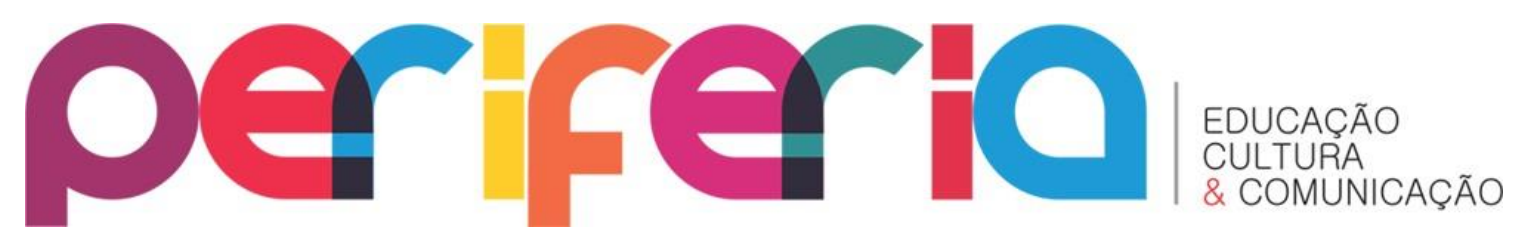

anunciados grandes investimentos na cidade, com a instalação das fábricas da FIAT e da Empresa Federal de Hemoderivados do Sangue - HEMOBRÁS.

Ademais, tal análise evidenciou a importância de estudos que através da abordagem da educação patrimonial em diálogo com o campo da história local buscam ressignificar práticas históricas e historiográficas que, partindo do local consigam dialogar e aproximar-se do contexto histórico nacional causando a valorização das memórias, do patrimônio e das identidades.

\section{REFERÊNCIAS BIBLIOGRÁFICAS}

AMORIM, M. A. Patrimônios vivos de Pernambuco. Recife: FUNDARPE, 2010.

ANDRADE, M. C. de. Itamaracá, uma capitania frustrada. Recife: FIDEM, 1999. 1997. . Pernambuco imortal: evolução histórica e social de Pernambuco. Recife: CEPE, . Pernambuco: cinco séculos de colonização. João Pessoa: Grafset, 2004.

AULETE, C. Dicionário contemporâneo de língua portuguesa. Rio de Janeiro: Nova Fronteira, 2004.

BARROS, J. D’A. Cidade e história. Petrópolis, RJ: Vozes, 2007.

O campo da história: especialidades e abordagens. Petrópolis, RJ: Vozes, 2004.

BOXER, C. R. Relações raciais no Império Colonial Português - 1415-1825. Rio de Janeiro: Tempo Universitário, 1980.

CASTRO, V. Das igrejas ao cemitério: políticas públicas sobre a morte no Recife do século XIX. Recife: Fundação de Cultura da Cidade do Recife, 2007.

CAVALCANTI E.; CABRAL, G. (orgs.). A história e suas práticas de escrita: relatos de pesquisa. Recife: Ed. Universitária UFPE, 2013.

COSTA, E. V. Da monarquia à república: momentos decisivos. 8. ed. São Paulo: UNESP, 2007.

GOIANA. Secretaria de Educação e Inovação - SECEDI. Goiana: cidade histórica. GoianaPE: SECEDI, 2010. 


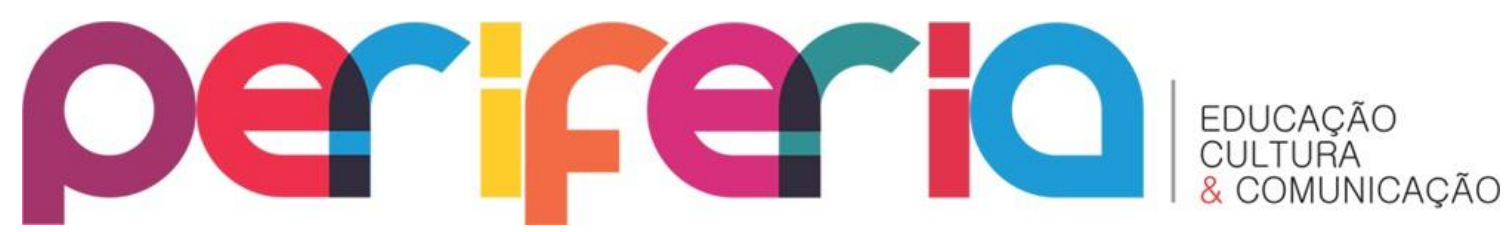

HONORATO, M. C. Dicionário topográfico, estatístico e histórico da Província de Pernambuco. Recife: SEDUC, 1976.

KOSTER, H. Viagens ao Nordeste do Brasil. 2. ed. Recife: SEDUC, 1978.

MACHADO, T. J. As insurreições liberais em Goiana, 1817-1824. Recife: FUNDARPE, 1990.

MARTINS, A. L. Fontes para o patrimônio cultural: uma construção permanente. In: PINSKY, C. B.; LUCA, T. R. (orgs.). O historiador e suas fontes. São Paulo: Contexto, 2009.

NASCIMENTO, M. R. Crônicas goianenses. Recife: Carlos Eduardo Carvalho dos Santos, 1996.

NORA, P. Entre memória e história: a problemática dos lugares. São Paulo: EDUSP, 1993.

RAMINELLI, R. História urbana. In: CARDOSO, Ciro F., VAINFAS, Ronaldo (orgs.).

Domínios da história: ensaios de teoria e metodologia. Rio de Janeiro: Campus, 1997.

PINTO, O. Velhas histórias de Goiana. Rio de Janeiro: Vecchi, 1968.

SENA, J. F. Goiana em versos e prosa. Recife: CEPE, 2008.

SILVA, S. V. Pretinha do Congo de Goiana: uma nação africana na Jurema da Mata Norte. Olinda-PE: Associação Reviva, 2011.

SOUZA, S. M. Goiana, a nossa pequena Pátria. Recife: Luci Artes Gráficas Ltda., 2005.

TOSH, J. Mapeando o campo: história local. In: A busca da história: objetivos, métodos e as tendências no estudo da história moderna. Petropólis, RJ: Vozes, 2011. 